\title{
Alcohol Poisoning in Toxicology Center of East Azarbaijan Province of Iran
}

\author{
Samad Shams Vahdati', Rouzbeh Rajaei Ghafouri', Sarvin Dalil², Sina Baghizadeh², Ali Ostadi ${ }^{3}$, Behjat Derakhti $^{4}$, Paria Habibollahi ${ }^{5}$ \\ 'Department of Emergency Medicine, Tabriz University of Medical Science, Tabriz, Iran \\ ${ }^{2}$ Faculty of Medicine, Tabriz University of Medical Science, Tabriz, Iran \\ ${ }^{3}$ Department of Forensic and Toxicology, Tabriz University of Medical Science, Tabriz, Iran \\ ${ }^{4}$ Department of M.s. In Critical Care, Shahid Beheshti University of Medical Science, Tabriz, Iran \\ ${ }^{5}$ Student Research Committee, Pharmacology and Toxicology Department, Tabriz University of Medical Science, Tabriz, Iran
}

\begin{abstract}
Aim: The prevalence of alcohol poisoning is increasing in Iran but there is not enough information regarding the relationship between the prevalence of alcohol abuse and demographic variables. We aimed to obtain data regarding the epidemiological aspect of alcohol abuse and its treatment methods and the fate of alcohol-poisoned patients.

Materials and Methods: This retrospective study was conducted on alcohol-poisoned patients who were referred to the Emergency Department of Sina Hospital from October 2011 to April 2012. Gender, age, marital status, social habit, type of alcohol consumed, time of alcohol consumption, chief complication, and type of treatment, and finally the outcomes of patients were recorded.

Results: There were 30 alcohol-poisoned patients during this period, including 29 males and only one female with a mean age of 37.6 years. Clinically, $66.6 \%$, $56.7 \%, 56.6 \%$, and $23.3 \%$ of the patients suffered from metabolic acidosis, consciousness and visual disturbances, and respiratory distress, respectively. In this study, $73.3 \%$ of the hospitalized patients underwent dialysis, $6.7 \%$ of the patients received ethanol or charcoal, $13.3 \%$ of the patients received ethanol and folic acid or other treatments, and $6.7 \%$ of the patients underwent intubation. Complete recovery was observed in $70 \%$ of the treated patients, while $16.7 \%$ of the patients experienced partial recovery and $13.3 \%$ of the patients died.
\end{abstract}

Conclusion: This study shows that in case of alcohol overdose or toxic level, we must take into account methanol and related side-effects, particularly in the patients who consume home-made alcohol. (Eurasian J Emerg Med 2015; 14: 131-3)

Keywords: Alcohol, methanol, poisoning

\section{Introduction}

Drug abuse and addiction are a chronic and recursive phenomena resulting in serious physical, financial, familial, and social losses (1). Although alcohol is widely used in western countries (2), in Iran, there is no comprehensive information regarding the consumption of alcohol and psychotropic drugs because of legal limitations (3). At present, the consumption of alcohol is one of the most important legal and medical problems, and it is one of the reasons for referring the patients to emergency departments (4).

Acute alcohol poisoning is a dangerous clinical condition resulting from its oral overuse (5).

Methanol is a colorless liquid mainly used as an industrial solvent and occasionally used in adulterated alcoholic drinks (6). There- fore, the consumption of adulterated alcoholic drinks may lead to poisoning with impurities, including methanol, in addition to complications resulting from ethanol (7).

Metabolism of methanol to formaldehyde and finally to formic acid followed by its overuse may lead to metabolic acidosis, respiratory distress, and optic nerve damage (8). Ethanol is suggested as a treatment for methanol poisoning. It results in a low production of poisonous metabolites of methanol. Then, the methanol remaining in the body is eliminated through hemodialysis (9). In these patients, the use of folate may also lead to an increased excretion of poisonous products of methanol (10).

The number of patients referred to emergency departments with symptoms of acute methanol poisoning is increasing in Iran. To prevent the long-term complications of methanol poisoning; therefore, it is necessary to diagnose and treat it early (11).

Correspondence to: Samad Shams Vahdati e-mail: sshamsv@gmail.com

Received: 07.10.2014 Accepted: 21.04.2015

(C) Copyright 2015 by Emergency Physicians Association of Turkey - Available online at www.eajem.com 
Most studies have referred to complications resulting from methanol poisoning as well as its treatment methods. However, there is a lack of sufficient information regarding the relationship between the prevalence of alcohol abuse and demographic variables in Iran. Thus, the present study considers the epidemiological aspect of alcohol abuse and its relationship with methanol poisoning, treatment methods, and finally, fate of methanol-poisoned patients.

\section{Materials and Methods}

This retrospective, cross-sectional, descriptive study was conducted on all patients poisoned with different types of alcohol and referred to the Emergency Department of Sina Hospital from October 2011 to April 2012. Patients with multi-drug poisoning or those who left the hospital with their own satisfaction were excluded from the study. The collected data include gender, age, marital status, social habit, type of alcohol consumed, time of alcohol consumption, and chief complication. Documents found in the Sina Hospital archive was used to complete the data, and the patients' information was recorded and kept confidential. Finally, Statistical Package for the Social Sciences (SPSS Inc., Chicago, IL, USA) 15 software was used to descriptively analyze the collected data.

This study was submitted to the Ethics Committee of the Tabriz University of Medical Science (no.5/4/3737).

\section{Results}

The present study evaluated 30 patients poisoned because of the consumption of alcohol and referred to and hospitalized at the Sina Hospital from October 01, 2011 to April, 2012. The patients comprised 29 (97.6\%) males and one (3.3\%) female. There were two (66.7\%) married and $10(33.3 \%)$ single patients. Mean age of the patients was 37.6 years (range, $20-30$ years) (Table 1 ).

Considering the history of smoking, consumption of alcohol, and use of narcotics and hookah, it should be mentioned that $8(26.7 \%)$ patients were referred only because of a history of alcohol consumption, 12 (40\%) patients were alcohol consumers and smokers, 4 (13.3\%) patients consumed alcohol and opiate, 2 (6.7\%) patients consumed alcohol and opiate as well as smoked cigarettes, and one (3.3\%) patient consumed opiate and smoked. The remaining three (10\%) patients had no record of alcohol consumption and other above mentioned habits.

Most patients (56.7\%) were referred to the center with complication from poisoning 24 hours after the consumption of alcohol (Table 2). Considering the type of alcohol consumed, 20 (66.7\%) patients consumed ethanol, 9 (30\%) consumed methanol, and only one (3.3\%) simultaneously consumed both ethanol and methanol (Figure 1).

Table 1. Mean age of patients referred because of poisoning with alcohol

\begin{tabular}{|l|c|c|}
\hline Age (years) & Frequency & $\%$ \\
\hline $10-20$ & 1 & 3.3 \\
\hline $20-30$ & 11 & 36.7 \\
\hline $30-40$ & 6 & 20 \\
\hline $40-50$ & 3 & 10 \\
\hline $50-60$ & 7 & 23.3 \\
\hline $60-70$ & 2 & 6.7 \\
\hline
\end{tabular}

In this study, 16 (53.3\%) and 12 (40\%) patients were referred to the hospital with a chief complication of consciousness and visual disturbances, respectively (Table 3). Clinically, 66.6\%, 56.7\%, 56.6\%, and $23.3 \%$ of the patients suffered from metabolic acidosis, consciousness and visual disturbances, and respiratory distress, respectively.

In this study, 22 (73.3\%) hospitalized patients underwent dialysis. Two (6.7\%) patients received ethanol or charcoal, 4 (13.3\%) patients received ethanol and folic acid or other treatments. In addition, $2(6.7 \%)$ patients underwent intubation.

Out of all the patients, 20 (66.7\%) patients were released with complete optical recovery, and 6 patients (20\%) were introduced to ophthalmology clinics.

Complete recovery was observed in $70 \%$ of the treated patients, while $16.7 \%$ of the patients experienced partial recovery and $13.3 \%$ patients died (Figure 2).

\section{Discussion}

According to studies, methanol poisoning was not common in the US, and it includes $1 \%$ of all poisoning cases $(12,13)$. According to reports, ethanol poisoning consisted of approximately $2 \%$ of all the poisoning cases in US in 1999 (12).

In their study regarding poisoning with ethanol, Masoumi et al. (11) studied 51 patients in Iran from 2000-2009. Patients comprised $83.4 \%$ males and $15.7 \%$ females. Mean age of male patients was

Table 2. Referring time after the consumption of alcohol

\begin{tabular}{|l|c|c|}
\hline Time & Frequency & $\%$ \\
\hline $1-6 \mathrm{~h}$ & 4 & 13.3 \\
\hline $6-12 \mathrm{~h}$ & 2 & 6.7 \\
\hline $12-18 \mathrm{~h}$ & 5 & 16.7 \\
\hline $18-24 \mathrm{~h}$ & 2 & 6.7 \\
\hline$>24 \mathrm{~h}$ & 17 & 56.7 \\
\hline
\end{tabular}

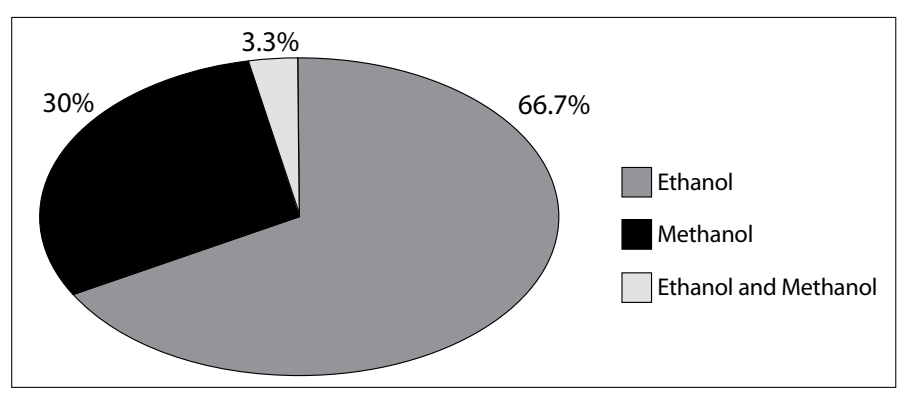

Figure 1. Type of alcohol consumed

Table 3. Chief complication of the patients when referred to the hospital

\begin{tabular}{|l|c|c|}
\hline Chief compliant & Frequency & $\%$ \\
\hline Consciousness disturbance & 16 & 53.3 \\
\hline Optical disturbance & 12 & 40 \\
\hline $\begin{array}{l}\text { Consciousness, optical, } \\
\text { and digestive system disturbances }\end{array}$ & 1 & 3.3 \\
\hline Dyspnea and other & 1 & 3.3 \\
\hline
\end{tabular}




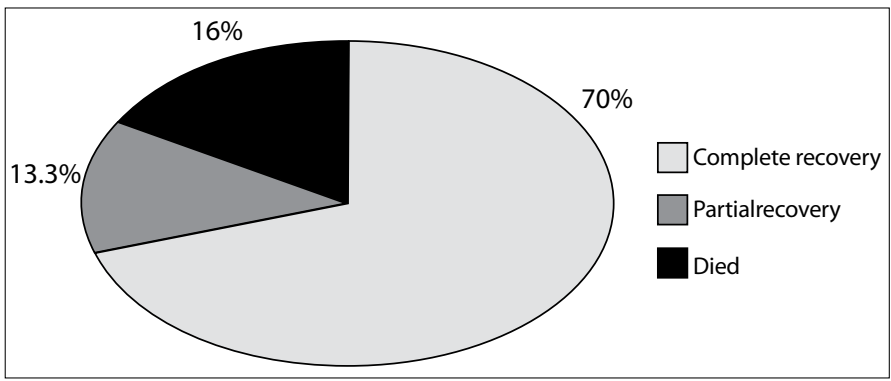

Figure 2. Final outcome of patients suffering from alcohol poisoning

$32.5 \pm 15.2$ and that of females was 20.1 \pm 7.5 . Most patients were aged between 20 and 29 years. In addition, four patients died, and 32 patients were discharged without any problem.

Similar to other studies where men consume alcohol more than women $(14,15)$, there were $97.6 \%$ male patients in our study. Mean age of the patients in our study was 37.6 years (20-30 years). Of these patients, 4 died and the remaining were discharged from the hospital with complete or partial recovery. According to the study conducted by Ekins BR et al. on seven patients hospitalized with ethanol poisoning, all patients survived. With an exception of one patient, all were released without any optical problem and optical nerve neuritis. They also concluded that the intravascular administration of ethanol solution (10\%) is an effective anti-death for patients with severe methanol poisoning (16).

Other studies concluded that different degrees of optical problems are seen in patients with alcohol poisoning. The highest rate of recovery is seen in those patients who underwent dialysis (17).

In our study, $56.6 \%$ of the patients suffered from optical disorder, and $73.3 \%$ of the patients underwent dialysis. Of these patients, 20 were discharged from the hospital without any optical problem, while six patients were released with partial recovery and were recommended to refer to ophthalmology clinics. In addition, four patients were excluded from the study because they died.

In their study, Liu (18) concluded that coma or convulsion seen in clinical symptoms as well as severe metabolic acidosis are indicators of weak prognosis in methanol poisoning. In our study, $56.7 \%$ and $66.6 \%$ of the patients suffered from consciousness disturbance and metabolic acidosis, respectively.

\section{Study limitations}

This study has been conducted within the limited time of the year; in addition, it was conducted in only one referral center. If we can conduct it in multiple centers with higher data, it may be better in aiding the decision making process.

\section{Conclusion}

In this study, we found that most of the alcohol users are young men who consume alcohol prepared in a home-made (unmanufactured) manner that result in methanol poisoning. In addition, most of them have the chief complaint of consciousness and visual disturbances.

Ethics Committee Approval: Ethics committee approval was received for this study from the ethics committee of Tabriz University (No.5/4/3737).
Informed Consent: To the retrospective nature of this study, informed consent was waived.

Peer-review: Externally peer-reviewed.

Conflict of Interest: No conflict of interest was declared by the authors.

Financial Disclosure: The authors declared that this study has received no financial support.

\section{References}

1. Kuo PH, Yang HJ, Soong WT, Chen WJ. Substance use among adolescents in Taiwan: associatedpersonality traits, incompetence, and behavioral/ emotional problems. Drug Alcohol Depend 2002; 67: 27-39. [CrossRef]

2. Lieber CS. Medical disorders of alcoholics. N Engl J Med 1995; 333: 105865. [CrossRef]

3. Ayatollahi AR, Mohammadpour A, Rajaee AR. Predicting the three stages of smoking among high school students in Shiraz Boys. Journal of Medical Sciences and Health Services 1383; 64: 10-15.

4. Haddad LM, Winchester JF. Clinical management ofpoisoning \& drug overdose. 2nd ed. Philadelphia:W.B. Saunders, 1990: 687.

5. Vonghia L, Leggio L, Ferrulli A, Bertini M, Gasbarrini G, Addolorato G, et al. Acute alcohol intoxication. Eur J Intern Med 2008; 19: 561-7. [CrossRef]

6. Williams GF, Hatch FJ, Bradley MC. Methanol poisoning: a review and case study of four patients from central Australia. Aust Crit Care 1997; 10: 113-8. [CrossRef]

7. Schonwald S. Medical toxicology. 1st ed. Philadelphia: Lippincott Williams \& Wilkins, 2001; 153: 162-4.

8. Martin-Amat G, McMartin KE, Hayreh SS, Hayreh MS, Tephly TR. Methanol poisoning: ocular toxicity produced by formate. Toxicol Appl Pharmacol 1978; 45: 201-8. [CrossRef]

9. Gonda A, Gault H, Churchill D, Hollomby D. Hemodialysis for methanol intoxication. Am J Med 1978; 64: 749-58. [CrossRef]

10. Becker CE. Methanol poisoning. Eurasian J Emerg Med 1983; 1: 51-8. [CrossRef]

11. Massoumi G, Saberi K, Eizadi-Mood N, Shamsi M, Alavi M, Morteza A. Methanol poisoning in Iran, from 2000to 2009. Drug Chem Toxicol 2012; 35: 330-3. [CrossRef]

12. Litovitz TL, Klein-Schwartz W, White S, Cobaugh DJ, Youniss J, Drab A et al. 1999 annual report of the American Association of Poison Control Centers Toxic Exposure Surveillance System. Am J Emerg Med 2000; 18: 517-74. [CrossRef]

13. Barceloux DG, Bond GR, Krenzelok EP, Cooper H, Vale JA. American Academy of Clinical Toxicology practice guidelines on the treatment of methanol poisoning. J Toxicol Clin Toxicol 2002; 40: 415-46. [CrossRef]

14. Rosón B, Monte R, Gamallo R, Puerta R, Zapatero A, Fernández-Solá J, et al. Prevalence and routine assessment of unhealthy alcohol use in hospitalized patients. Eur J Intern Med 2010; 21: 458-64. [CrossRef]

15. Kandel D, Chen K, Warner LA, Kessler RC, Grant B. Prevalence and demographics correlates of symptoms of last year dependence on alcohol,nicotin, marijuana and cocaine in the U.S. population. Drug Alcohol Depend 1997; 44: 11-29. [CrossRef]

16. Ekins BR, Rollins DE, Duffy DP, Gregory MC. Standardized treatment of severe methanol poisoning with ethanol and hemodialysis. West J Med 1985; 142: 337-40.

17. Shah S, Pandey V, Thakore N, Mehta I. Study of 63 cases of methyl alcohol poisoning (hooch tragedy in Ahmedabad). J Assoc Physicians India 2012; 60: 34-6.

18. Liu JJ, Daya MR, Carrasguillo O, Kales SN. Prognostic factors in patients with methanol poisoning. J Toxicol Clin Toxicol 1998; 36: 175-81. [CrossRef] 